\title{
STUDIES ON THE REPRODUCTIVE STATUS, CATCH AND AGE COMPOSITIONS OF THE TSETSE FLY, GLOSSINA PALLIDIPES POPULATIONS IN THE NECHISAR NATIONAL PARK IN SOUTHERN ETHIOPIA
}

\author{
Abebe Hailemariam ${ }^{1}$, Emiru Seyoum ${ }^{2}$ and Mark Vreysen ${ }^{3}$ \\ ${ }^{1}$ Awassa College of Teacher Education, PO Box 115, Awassa, Ethiopia \\ ${ }^{2}$ Faculty of Science, Addis Ababa University, PO Box 1176, Addis Ababa, Ethiopia \\ ${ }^{3}$ Tsetse Eradication Project, Ethiopian Science and Technology Commission, Addis Ababa, Ethiopia
}

\begin{abstract}
Studies were conducted during the dry hot period of December 1999 to April 2000 in the Nechisar National Park, Southern Ethiopia, to obtain base line data on catch, age compositions, and reproductive status of samples of Glossina pallidipes, trapped in NGU-2G traps. The objective was to assess tsetse population dynamics and to provide data on the temporal and spatial variations of the structure of the fly population at five localities (habitats). The data were to be used for the suppression phase of a Sterile Insect Technique (Sाт) project in the study area. Population study in space was conducted at randomly selected five sites in and out of the park. In each vegetation type, a set of 2 NGU-2G traps baited with urine and acetone were deployed for five days during the same week of the study time. Female flies were dissected to assess ovarian age structure of populations. To determine the age of male flies wing-fray analysis was carried out using wing-fray categories (1-6). Trapped tsetse included significantly higher proportions of teneral and non-teneral females, and a lower male: female ratio. Insemination rates of the sampled flies were over $95 \%$ at all habitats. In any one habitat, the frequency of pregnancy (egg stage) predominated, followed by the first, second, and lastly, by the third instar larva. Abortion was the predominant reproductive abnormality at all habitats of the natural population of G. pallidipes. Age compositions of females (ovarian aging) showed greater proportions of females with 13 ovarian age categories and a physiological age between 8-40 days at all habitats. Age compositions of males (wing-fray) were significantly greater for young males (1-3 wfc) compared with old males (4-6 wfc). The studies of this base line data collection with other operational studies will be a prerequisite to assess the feasibility of the proposed area wide eradication project and to develop appropriate strategies to suppress and finally to eradicate the fly by situational releases of sterilized male flies.
\end{abstract}

Key words/phrases: Abortion, age reproductive status, Glossina pallidipes, NGU-2G traps, pregnancy

\section{INTRODUCTION}

From an economic point of view, tsetse and trypanosomiasis pose big constraints on rural development and discourages human settlement. This further prevents the keeping of animals, especially cattle for meat and milk. Tsetsetransmitted animal trypanosomosis is one of the Ethiopian most important livestock development problems. The livelihood of some five million people is directly or indirectly negatively affected by the presence of the tsetse fly and the disease it transmits to livestock. The on-going effort on tsetse and trypanosomes management is supplemented by the sterile insect technique, using an area wide eradication approach against Glossina pallidipes.

Previous studies show that five species of Glossina occur in Ethiopia including G. pallidipes, $G$ .fuscipes, G. morsitans, G. tachinoides, and G. longipennis (Langridge, 1976; Fuller, 1978). New information on the distribution of most of these species is generally lacking, although Assefa Mebrate (2000) had reported that an estimated 150,000 to 200,00 $\mathrm{km}$ square of land in the fertile valleys of the south, west and north west Ethiopia is believed to be infested with one or more of the five known tsetse fly species that are vectors of animal trypanosomosis.

On the other hand, G. pallidipes in the southern rift valley of Ethiopia has extended its altitudinal range from 1,700 m.a.s.l. (Langridge, 1976) to 1992 m.a.s.l. (Vreysen, 1999). Although, introduction of livestock is prohibited in the natural reserve of the park, trypanosomosis is a major livestock problem in the area transmitted by G. pallidipes.

Currently there is no sufficient data on temporal and spatial variations of the population structure of G. pallidipes in the area. This study was aimed to obtain base line data on population and age composition, and reproductive status of trapped samples of G. pallidipes. Extensive base line data of tsetse populations on related abundance, seasonal fluctuations in population densities, spatial distribution pattern and its seasonal changes are a prerequisite if control or eradication of target pest/vector species is attempted. The data collected in this base line study give information for the fly suppression program before the sterile insect technique is employed. This data will be a prerequisite to assess the feasibility of the 
proposed area wide eradication project and to develop appropriate strategies to suppress and finally to eradicate the fly by sequential releases of steril male flies. This information should however be complemented with in depth data on the ecology and behaviour of G. pallidipies.

The present study was, therefore, an integral part of the joint project of the Ethiopian Science and Technology Commission (ESTC) and the International Atomic Energy Agency (IAEA), which over time aims to eliminate the tsetse from $25,000 \mathrm{~km}^{2}$ of potential agro-pastoral land in the southern rift valley of Ethiopia using SIT (ESTC/IAEA, 1998).

\section{MATERIALS AND METHODS}

\section{Study area}

The study was conducted in four selected and defined habitats of Nechisar National Park and in one habitat outside the park, during the hot-dry months of December 1999 to April 2000. The Park is situated in the rift valley of southern Ethiopia with a total surface area of 75,200 ha (Fig. 1).

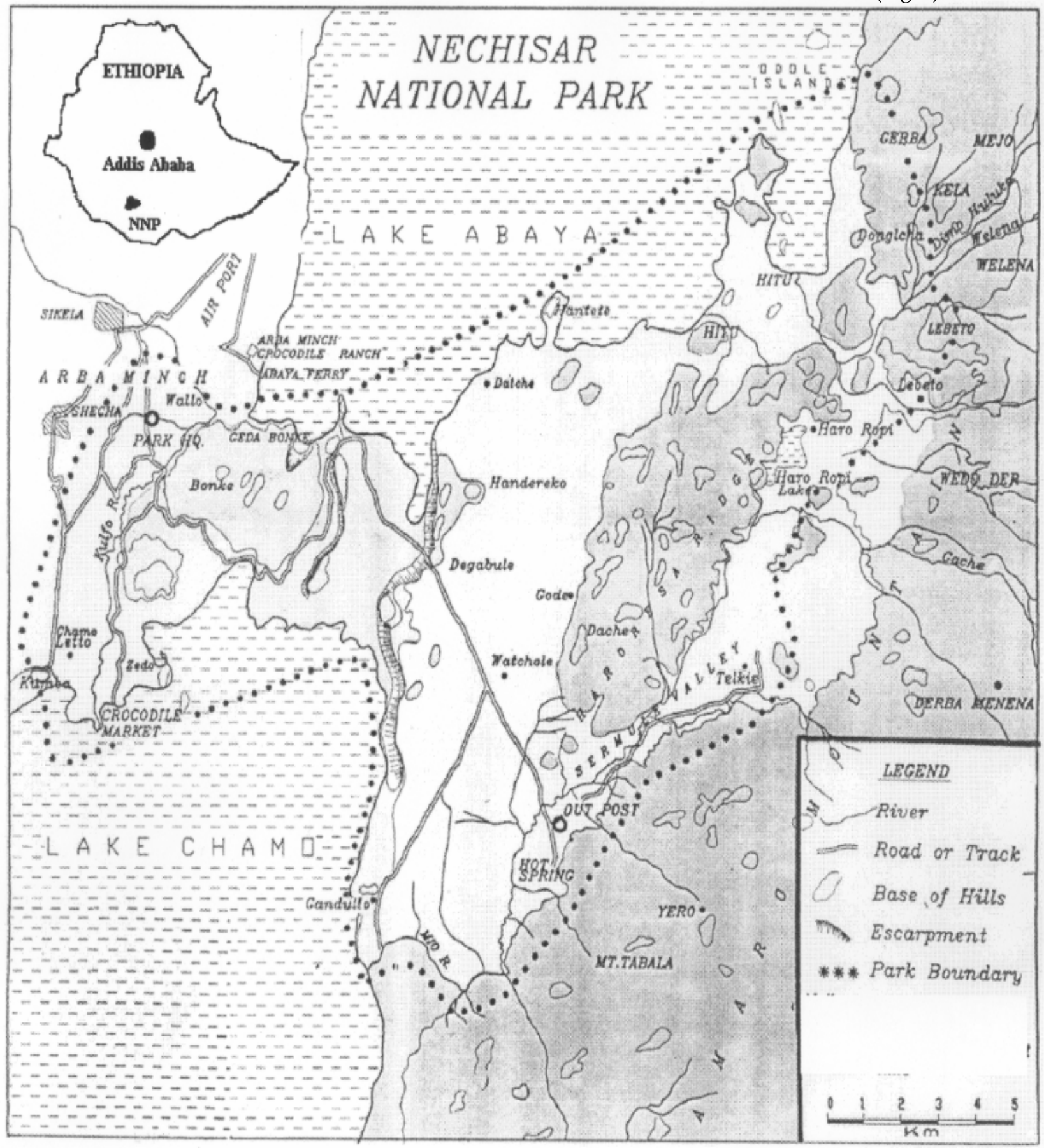

Fig. 1. The study area -Nechisar National Park (NNP). 
The centre of the park is composed mainly of gently undulating grassland with scattered bare rocky and bushy areas. Two rivers (Kulfo and Sermale) are found within the area and are lined with riverine forest and a small ground water. The park is bordered in the east by the Amaro Mountains, in the west by the town of Arbaminch, in the north and south by Lakes Abaya and Chamo, respectively.

The rainy season starts from April and peaks around August to October. During the study period the average monthly temperatures ranged from $32-36^{\circ} \mathrm{C}$ with a corresponding relative humidity between $45 \%$ and $52 \%$. The vegetative cover of the study sites were selected and defined as bush land (BUL), woody grassland (WGL), riverine forest $(\mathrm{RF})$, ground water forest $(\mathrm{GWF})$, and cultivated land (CUL). The vegetation is composed mainly of Acacia tortilis, Acacia seyal, Heteropogan contortus, Lintonia nutanus, Ficus sycomorus, Cordia africana, Diospyros abyssinica. Cultivated crops on CUL habitats included Ensete ventricosum, Mangifera indica, and Lantana camara. Host animals detected from direct sighting and reports of Ethiopian Wild Life Conservation Organization (EWLCO, 1999), were mainly of warthogs, bush pigs, bushbuck, greater kudu, Burchelle's zebra, buffalo, lions, wild dogs, Colobus and Vervet monkeys, including a great number of bird species.

\section{Catch of tsetse fly}

Flies were caught by NGU-2G traps (Brightwell et al., 1991) (Fig. 2). Two traps were deployed for continuous 24 hours trapping at each of the five habitat types for five days (120 hours) during the same week of the sampling months. Traps were installed $100 \mathrm{~m}$ apart and baited with acetone and cow urine (FAO, 1982). The traps were mounted as described by Verysen (1999). Trapped tsetses were collected from top cages two times per day from 08-09 hours and 14-15 hours.

\section{Dissection}

Tsetse flies caught with NGU-2G traps were killed with forceps, counted, sexed and examined for tenerality as described by Murray et al. (1983). Ovarian method was used to determine the age of female flies (Saunders, 1962; Chalier, 1965). During dissection, inseminations, uterine contents, abortions and ovarian abnormalities were recorded. An inseminated female with an empty uterus was designated as aborted, irrespective of whether an ovariole contained a mature egg or not.

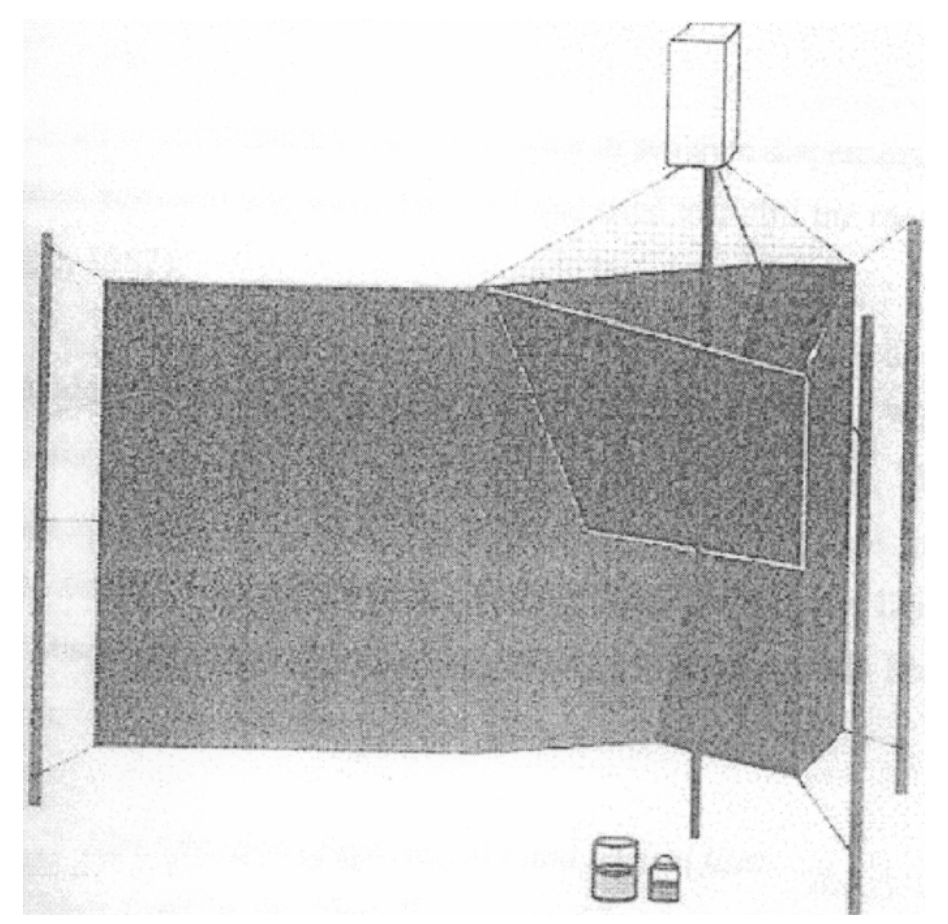

Fig 2. The Nug-2g Trap with its one meter blue wing extension. 


\section{Data analysis}

Differences in the proportions of the age, wingfray, uterus content and sex ratio were analyzed using Chi-square with the help of the MSTAT-C statistical package.

\section{RESULTS}

The total catch of G. pallidipes at the five different habitats of the study area is presented in Table 1. The results show that the overall number of flies captured in the NGU-2G trap was made up of teneral and non-teneral females $52.49 \%$ which are
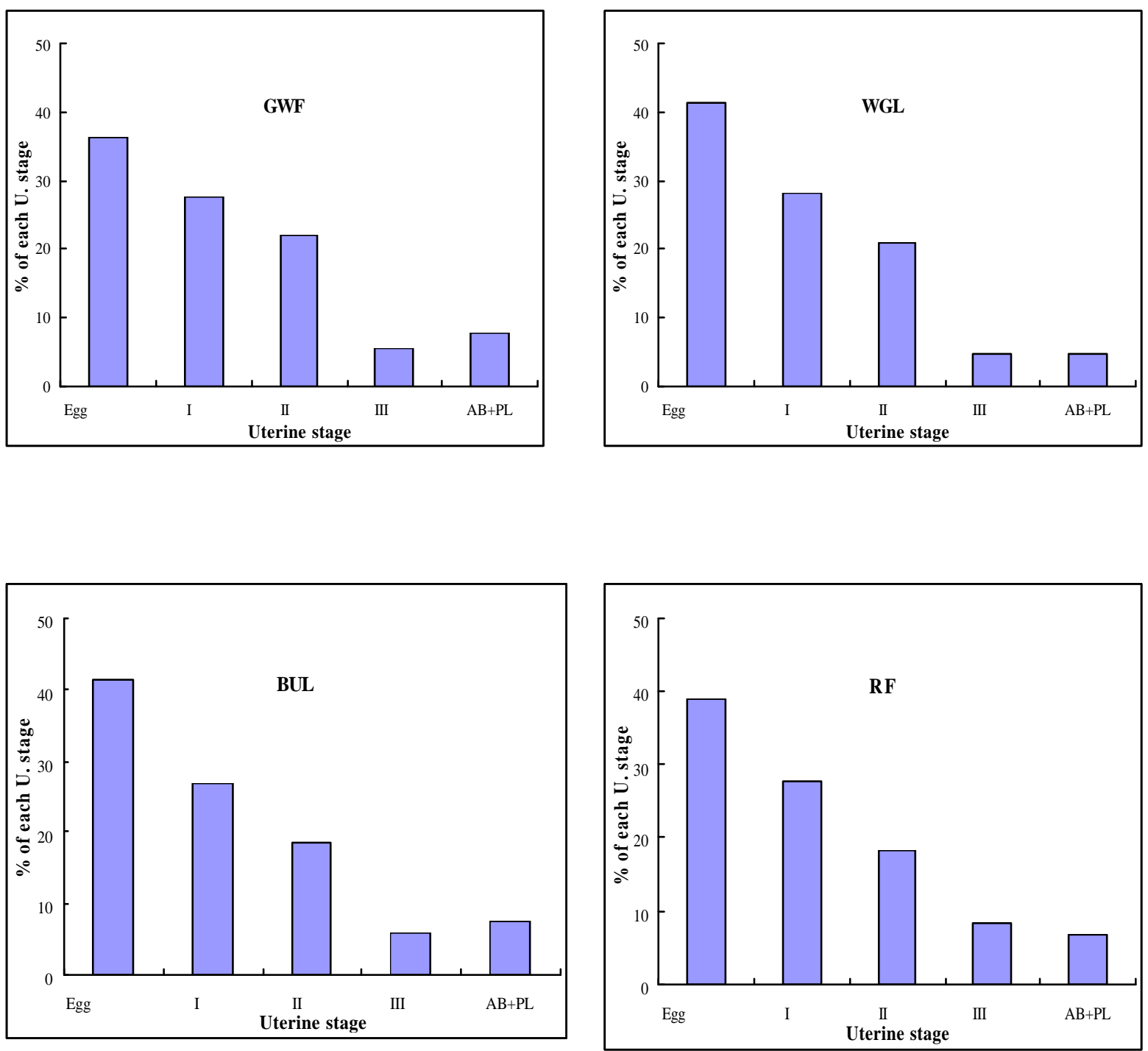

Fig. 3 a-d. Uterine stages of trapped samples of Glossina pallidipes in four habitats of Nechisa National Park, Ethiopia.

[Egg, I-first la rva, II+III -second \& third larva (pooled). AB+PL abortion \& other reproductive abnormalities (pooled)]. 
The average age composition of females caught in traps at the five vegetation types (habitats) over the study period are shown in Fig 2a-e. In general, there were significance differences between ovarian age categories (0-7) and the sampling months at each habitat type: WGL $\left(\chi^{2}=83.57 ; \mathrm{df}=16\right.$; $\mathrm{p}<0.0000), \quad$ BUL $\quad\left(\chi^{2}=55.00 ; \quad \mathrm{df}=6 ; \quad \mathrm{p}<0.000\right), \quad \mathrm{RF}$ $\left(\chi^{2}=78.22 ; \mathrm{df}=16 ; \mathrm{p}<0.000\right), \mathrm{GWF}\left(\chi^{2}=77.41 ; \mathrm{df}=16\right.$; $\mathrm{p}<0.000)$ and CUL $\left(\chi^{2}=37.82 ; \mathrm{df}=16 ; \mathrm{p}<0.002\right)$.
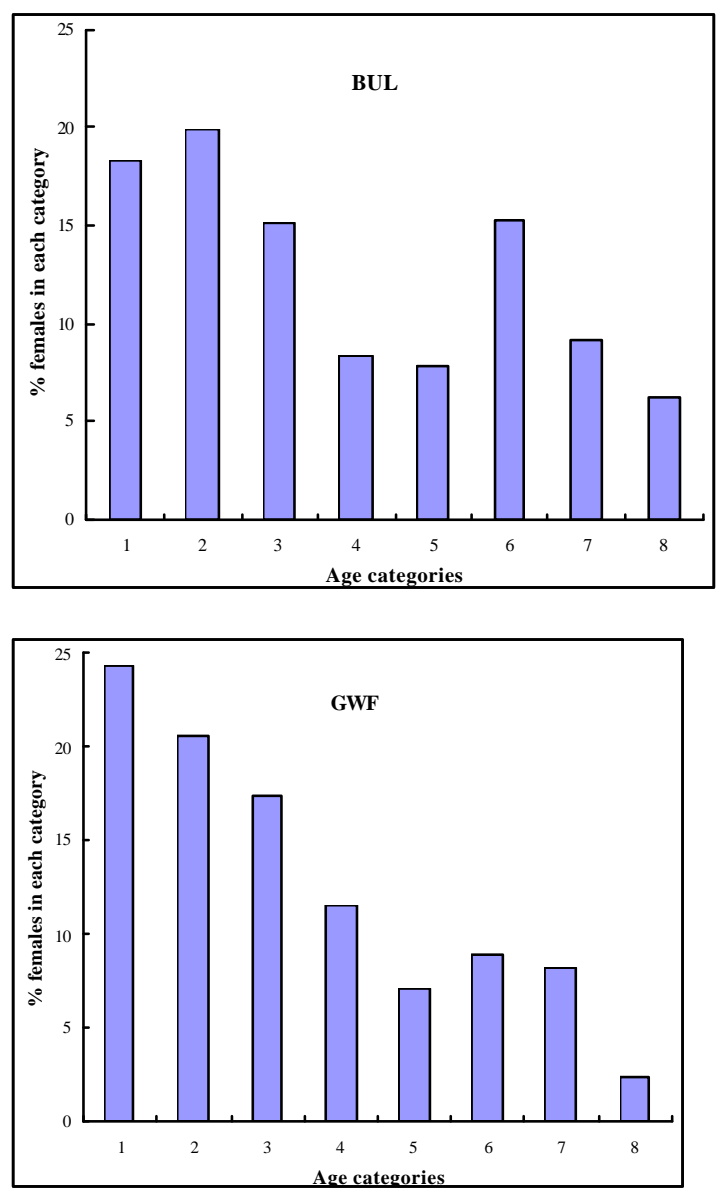

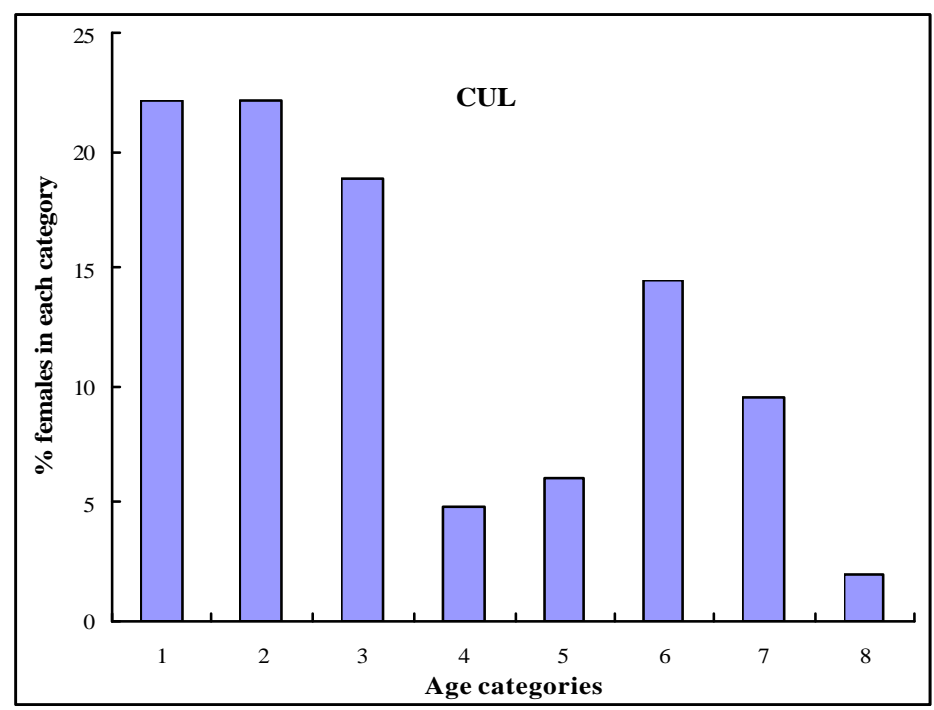

Fig. 4a-e. Age compositions of trapped samples of G. pallidipes in Nechisar National park, Ethiopia. 
Table 1. Total catches of G. pallidipes at five different habitats from December 1999-April 2000.

\begin{tabular}{lccc}
\hline \multirow{2}{*}{ Habitat type } & \multicolumn{3}{c}{ No. of G. pallidipes } \\
\cline { 2 - 4 } & Males & Females & Total \\
\hline Woody grass land (WGL) & 2219 & 2194 & 4413 \\
Bush land (BUL) & 1400 & 1509 & 2909 \\
Riverine Forest (GWF) & 3313 & 3558 & 6871 \\
Ground Water Forest & 469 & 904 & 1373 \\
(GWF) & & & \\
Cultivated Land (CUL) & 299 & 343 & 642 \\
\hline Total & 7700 & 8508 & 16208 \\
& $47.51 \%$ & $52.49 \%$ & \\
\hline
\end{tabular}

The age composition of males caught in traps at each habitat type as determined by wing fray categories 1-6 are shown in Table 2. The results show that there was a significant difference between the wing fray categories (1-6) and habitat type during the sampling months.

Young males (1-3 wing fray groups) comprised $79.76 \%$ at GWF, $63.84 \%$ at BUL, $61.68 \%$ at $\mathrm{RF}, 58.42 \%$ at WGL $57.92 \%$ at CUL habitats compared with old males (4-6 wing fray groups) at each habitat type. Significant differences between wing fray categories (1-6) during the sampling months at each habitat were recorded: WGL $\left(\chi^{2}=46.97 \%\right.$; $\mathrm{df}=20 ; \mathrm{p}<0.001)$ BUL $\left(\chi^{2}=32.77 ; \mathrm{df}=20 ; \mathrm{p}<0.036\right), \mathrm{RF}$ $\left(\chi^{2}=49.09 ; \mathrm{df}=20 ; \mathrm{p}<0.000\right)$ GWF $\left(\chi^{2}=37.46 ; \mathrm{df}=20\right.$; $\mathrm{p}<0.010)$ and $\mathrm{CUL}\left(\chi^{2}=75.28 ; \mathrm{df}=20 ; \mathrm{p}<0.000\right)$.

\section{DISCUSSION}

Different sampling methods have been reported to produce catches of tsetse, which differs in numbers, physiology and trypanosome infections (Jordan, 1974; Randolph and Rogers, 1981). The higher number of female $G$ pallidipes (52.49\%) caught at all habitats may be explained in relation to the fact that, the longevity of female flies is more on the average, than that of male tsetse flies, (FAO, 1982; Amare Berhanu, 1995). Turner (1980) had previously showed in Niger and Mozambique that the use of traps differ from other sampling methods in that they caught more females than males of G. pallidipes. It was also reported that mortality rates of male flies in a natural population of tsetse results in higher densities of females (Goutex and Bucklandes, 1984).

However, the greater number of male flies at WGL habitat might be a function of the trapping sites and the sexually appetitive form of behaviour on the part of the male flies. This argument is in agreement with that of Buxton (1955).

In the present work, the high insemination rates recorded in all samples at all habitats indicated that the population of G. pallidipes in Nechisar National Park was a healthy one, and had a high male/female encounter which ensured the insemination of a large number of non-teneral females within the population. The finding that most tenerals were inseminated suggests that female adults of G. pallidipes in the park mate successfully within $24 \mathrm{hr}$. of eclosion, and probably even before obtaining their first blood meal.

In this study, a higher proportion of females that were pregnant with egg, first, second and third instar larval was observed in all samples of flies in time and space. This finding is generally in agreement with the works of Saunders (1962), Randolph and Rogers (1981) and Mohammed Ahmed and Dairri (1987) who reported similar frequency of encounter of pregnancy stages in tsetse samples.

Table 2. Wing fray categories (1-6) of male Glossina pallidipes, overall samples analyzed from December 1999April 2000.

\begin{tabular}{ccccccccccc}
\hline \multirow{2}{*}{ Habit type } & \multirow{2}{*}{ Sample size } & \multicolumn{7}{c}{ Wing fray categories \% } & \multirow{2}{*}{$\chi^{2}$} & P \\
\cline { 3 - 9 } & & 1 & 2 & 3 & 4 & 5 & 6 & & \\
\hline WGL & 625 & 27.28 & 12.38 & 18.76 & 12.4 & 17.14 & 11.98 & $46.97(20)$ & 0.001 \\
BUL & 435 & 27.44 & 17.34 & 19.06 & 12.26 & 14.06 & 9.84 & $32.27(20)$ & 0.036 \\
RF & 978 & 25.84 & 14.64 & 21.2 & 11.48 & 14.88 & 11.96 & $49.09(20)$ & 0.000 \\
GWF & 378 & 54.46 & 11.62 & 13.68 & 8.34 & 5.54 & 6.36 & $37.46(20)$ & 0.010 \\
CUL & 190 & 32.06 & 13.92 & 11.94 & 12.14 & 23.32 & 6.64 & $75.28(20)$ & 0.000 \\
\hline
\end{tabular}


The results of this study also show that female flies with the III instar larva were greatly under represented in the samples. This was probably due to the activity of pregnant G. pallidipes, which normally becomes readily available for capture just after larviposition (Turner, 1987). On the other hand, the preponderance of flies pregnant with the first instar larva over those with the II + III instar larva, can be explained by the fact that late pregnant females do not feed and remain inactive until larviposition and hence are unavailable for capture in the field (Rogers, 1978).

In natural tsetse population, reproductive abnormalities other than abortion are rare (Saunders, 1962; Turner and Snow, 1984). The type and frequency of ovarian abnormalities noted in the present study are within the range recorded for the same species of tsetse, in Kenya by Turner and Snow (1984). Since, extensive control measures have never been deployed against tsetse in the Nechisar National Park, the abortions and reproductive abnormalities are probably the main causes of natural reproductive loss in the population of G. pallidipes in the study area.

In tsetse, it is possible to determine the age of females accurately by the ovarian method (Challier, 1965) up to age group 3 (4th reproductive cycle). The remaining flies are composite groups from which it is impossible to tell whether an individual is in age category 4 (5th reproductive cycle) or $4+\left(=9^{\text {th }}---13^{\text {th }}---\right.$ etc. cycles $)$. The same is applicable for females at age category 5 or $5+, 6$ or $6+$ and 7 or $7+$. Assuming a similar sampling bias for females at $4+$ to $7+$ categories, it was observed that relatively fewer old females $(4+=7+$ ovarian age categories) could be recorded in most habitats as compared with young females (1-3 ovarian age categories). One reason for the lower survival rate of such older females might be the excessive wingfray resulting, presumably, from organic degradation of wings with age. Allsop (1985) observed in Botswana that, old females of G.m. centeralis had a higher degree of wing-fray, and this might have been the factor that limited the survival opportunities of most females of G. pallidipes dissected at each habitat in the park, from December 1999-April 2000. Yong females (1-3 ovarian age categories) were high in proportion in all habitats, compared with the pre-reproductive (0) and old females (4-7 ovarian age categories). Hence, young females with a physiological age between 8-40 days old were dominant in the order of $49.14 \%$ at GWF, $45.88 \%$ at CUL, $44.92 \%$ at WGL, $42.82 \%$ at RF and $41.2 \%$ at BUL habitats. Old females with a physiological age between $40-80$ days were followed in the order of $40.82 \%$ at $\mathrm{RF}, 39.78 \%$ at WGL, $38.52 \%$ at BUL, $32.08 \%$ at CUL and $26.58 \%$ at GWF habitats. These findings agree with the earlier works of Turner (1987) in Kenya who reported that trap captures of G. pallidipes was representative of the active population with respect to pregnancy condition and age-structure.

The importance of a study such as this one is the fact that the age composition of the samples at different habitats may serve as a guide to the importance of the tsetse flies as vectors of trypanosomes. Although, the duration of the development of trypanosomes within the fly is dependent upon temperature, the generally accepted period between infection and the appearance of metacylics in the proboscis or salivary glands is about 14 days or less in the case of Vivax group and about 21 days in brucie group (Saunders, 1962; FAO, 1982; Getachew Tikubet, 1983). It is, therefore, probable that flies younger than 14 days of age could be potential vectors. The proportionally higher groups of young females (between 8-40 days of age) followed by older females (between 40-80 days old) in our study agrees with the above explanations, although trypanosome infections in natural population of tsetse increases with age as reported by Leak and Rowlands (1997). This result in this base line study indicates the need for control of G. pallidipes in the Nechsar National Park, in order to reduce the potential infection of domestic animals with trypanosomes.

The results of the wing-fray analysis for male flies showed that, at the various habitat types (except at CUL habitat) in April 2000, the proportion of young males with 1-3 wing-fray categories were significantly greater than the proportion of old males with 4-6 wing-fray categories. It can, therefore, be concluded from 
such observations that young males were mostly favoured by the climatic conditions of the hot dry months of the area with a subsequent higher mortality in the older age groups. As reported by Leak and Rowlands (1997), the rate of wing-fray could vary seasonally and with locality between species of tsetse. It is unlikely that artificial damage significantly affected the results obtained in samples collected two times per day from top cages because the nature of wing-fray structure of male flies had many low wing fray categories.

Variations in the proportions of wing-fray categories 1-6 at each habitat type were noted. For instance the proportion of male flies with wingfray category one was significantly higher than that of other wing-fray categories. This significantly higher number of teneral and young male G. pallidipes ( $\mathrm{wfc}=1$ ) at each habitat supports the findings of Vale (1980) who showed that the large percentage of teneral populations can be used in a field sterilization program for successful control of trypanosomosis.

The information obtained in this study is probably vital for initiation of eradication control programs for tsetse flies in the study area. The knowledge of the physiological conditions and the sex ratio of $G$. pallidipes in the study area has revealed important information on the biology, ecology and behaviour of the insect. Furthermore, the information provided on the age-structure of these species as determined by the simultaneous application of wing-fray and ovarian age grouping methods could help in predicting and extrapolating the future fly-population trends and risks of trypanosome infections in the study area.

Although the present study provides valuable data on the temporal and spatial variations in the structure of tsetse fly population in the study area, the sampling bias observed in the different sampling techniques should be further assessed. It has also been clear that accurate integration of data on fly population structure will only be possible if the fraction of the fly population is sampled with the different sampling tools.

\section{CONCLUSION}

The present basic study of the population dynamics of G. pallidipes was conducted in a peculiar area where different habitats harbour different densities of fly populations. It was also noted that this species has penetrated into the village centre (cultivated open land), although the mean apparent density was low. Such a penetration potentially predisposes human inhabitants to trypanosome infection.

The occupation of space by the different age groups of females and males of G. pallidipes is not a hazardous phenomenon. This is because there is re-grouping in relation to ecological affinities, which varies according to the age of the individuals. Dissection of female flies for the study of the age compositions of samples revealed variation at different stages of the reproductive cycle. The highest proportions of females were grouped in ovarian age categories 1-3 as young females in time and space compared with the prereproductive (0) and old age (4-7) ovarian age categories.

The wing-fray categories (1-6) of male G. pallidipes demonstrated that young males (1-3) wing-fray categories were dominant at GWF followed by BUL, WGL, CUL and RF habitats. High proportion of young males were observed in this study and this suggests that early fertilization of young females can take place as copulation is likely to occur when females are attracted to the host for their first blood meal.

\section{ACKNOWLEDGEMENTS}

The authors are grateful to Drs. N.G. Maniania and Sunday Ekesi from ICIPE for their comments on the manuscript. We also thank the ESTC/IAEA tsetse eradication project for their technical and material support during the fieldwork and to their unfolding interest in the research undertakings. 


\section{REFERENCES}

1. Allsop, R. (1985). Wing-fray in G. morsitans centeralis. Bull. Entmol. Res. 75:1-11.

2. Amare Berhanu (1995). Preliminary survey on tsetse distribution and prevalence of Bovine Trypanosomiass in selected Weredas of the North Omo and Kembata -Alaba - Tembaro Zones. DVM Thesis submitted to the Faculty of Veterinary Medicine, AAU, pp. 1-9.

3. Assefa Mebrate (2000). Integrating the Sterile Insect Technique as a component of the tsetse eradication effort in Africa, the Ethiopian Experience: A paper Hall, from June 19-20/2000 in Addis Ababa, Ethiopia, pp. 1-7.

4. Brightwell, R., Dransfield, R.,D. and Kyorku, C. (1991). Development of a low-cost tsetse trap and oduour baits for G. pallidipes and G. longipennis in Kenya. Med. Vet. Entomol. 5:153-164.

5. Buxton, P.A. (1955). The Natural History of Tsetse Flies. An account of the Biology of the Genus Glossina (Diptera). Mem. Lond. Sch. Hyg. Trop. Med. №. 10, 816 pp.

6. Challier, A. (1965). Amelioration de la method de determination de 1'age physiologique des glossines. Etudes faites sur Glossina palpalis gombiensis Vander plank, 1949. Bull. de la Societe' de pathologie Exotique 58:250-259.

7. ESTC/IAEA (1998). Tsetse eradication by SIT from the southern rift valley of Ethiopia A bi-lateral agreement document between the Ethiopian Science and Technology Commission (ESTC) and the International Atomic Energy Agency (IAEA), Addis Ababa and Vienna, pp. 34-35.

8. FAO (1982). Basic Techniques for the Study of Glossina in the Field, pp. 91-119, (Pollock, J.J., ed.) Training manual for tsetse control personnel. Volume 1, FAO, Rome.

9. Fuller, G.K. (1978). Distribution of Glossina in South Western Ethiopia. Bull. Entomol. Res. 68:299365.

10. Getachew Tikubet (1983). Studies on the tsetse flies of the Fincha River valley. M.Sc. thesis, School of Graduate Studies, Addis Ababa University, 83 pp.

11. Gouteux, J.P. and Bucklands, S.T. (1984). Ecologie des glossines en sectear preforestier de C'ote D'Ivoire. Dynamic de I'ecodistribution en terroir villageois. Ent. Med. Parasi. XX (3):199-229.
12. Jackson, C.H.N. (1946). An artificially isolated generation of tsetse flies (Diptera). Bull. Entmol. Res. 37:291-199.

13. Jordan, A.M. (1974). Recent developments in the ecology and methods of control of tsetse flies Glossina spp. (Diptera). Bull. Entomol. Res. 63:361-399.

14. Leak, S.G.A. and Rowlands, G.J. (1997). The dynamics of trypanosome infections in natural populations of tsetse (Diptera) studies using wing-fray and ovarian aging techniques. Bull. Entmol. Res. 87:273-282.

15. Langridge, W.P. (1976). A Tsetse and Trypanosomiasis Survey of Ethiopia. Ministry of overseas Development, Britain, 98 pp.

16. Mohammed-Ahemed, M.M. and Dairri, M.F. (1987). Trypanosome infections rate of G. pallidipes during wet and dry seasons in Somalia. Trop. Anim. Health prod. 19:11-20.

17. Murray, M., Trail, J.C.M., Turner, D.A. and Wissocq, Y. (1983). Livestock Productivity and Trypanotolerance, Network Training Manual. Jointly published by ILRAO/ILCA and ICIPE, Nairobi, Kenya, 509 pp.

18. Randolph, S.E. and Rogers, D.J. (1981). Physiological correlates of the availability of G. morsitans centralis to different sampling methods. Ecol. Entmol. 6:63-77.

19. Rogers, D.J. (1978). Metabolic strategies of male and female tsetse (diptera) in the field. Bull. Entomol. Res. 68:639-654.

20. Saunders, D.S. (1962). Age determination for female tsetse flies and the age composition of samples of G. pallidipes Austen, G. palpalis and G. brevipalpis Newsten. Bull. Entomol. Res. 53:579-595.

21. Turner, D.A. (1980). Tsetse Ecological studies in Niger and Mozambique: I. Population sampling. Insect Science and its Application 1:9-13.

22. Turner, D.A. and Snow, W.F. (1984). Reproductive abnormality and loss in natural populations of G. pallidipes Austen (Diptera) in Kenya. Bull. Entomol. Res. 74:299-309.

23. Turner, D.A. (1987). The Population ecology of Glossina pallidepes Austen (Diptera Glossinidae) in the Lambwe Valley, Kenya. Feeding behaviour and activity patterns. Bull. Entomol. Res. 77:317333.

24. Vale, G.A. (1980). Field studies of the response of tsetse flies and other Diptera to carbon dioxide, 
acetone and other chemicals. Bull. Entomol. Res. 70:563-570.

25. Vreysen, M. (1999). Entomological field survey report on tsetse species composition and distribution in the project area from December 1998 - September 1999. Entomological Survey Team of the SIT project, Addis Ababa, Ethiopia, pp.1-32. 